\title{
Long-term follow-up of corticosteroid injection for traumatic olecranon bursitis
}

\author{
PHILIPS. WEINSTEIN, JUAN J. CANOSO, AND \\ JEFFREY R. WOHLGETHAN
}

From the Rheumatology Section and Medical Service, Boston Veterans Administration Medical Center, and the Arthritis and Connective Tissue Disease Section, Boston City Hospital and University Hospital, and the Arthritis Center of Boston University, Boston, MA, USA

SUMMARY Forty-seven patients with traumatic olecranon bursitis were evaluated after a mean follow-up of 31 months (range 6 to 62 months). Twenty-two patients treated with bursal aspiration . had delayed recovery and no complications of therapy. Twenty-five patients treated with intrabursal injection of $20 \mathrm{mg}$ of triamcinolone hexacetonide had rapid recovery, usually within one week, but suffered complications such as infection ( 3 cases), skin atrophy ( 5 cases), and chronic local pain ( 7 cases). Since spontaneous resolution can be expected, a conservative approach is suggested in the treatment of traumatic olecranon bursitis.

While the clinical ${ }^{1}$ and radiological ${ }^{2}$ findings in traumatic olecranon bursitis have been described in detail, the clinical course and long-term results of therapy remain largely unknown.

We report here the outcome of treatment of 47 consecutive patients with traumatic olecranon bursitis treated with bursal aspiration alone or aspiration followed by corticosteroid injection.

\section{Patients and methods}

Sixty male patients with traumatic olecranon bursitis were studied at the Rheumatology Section of the Boston Veterans Adminstration Medical Center from 1 July 1974 to 1 February 1980 . The diagnosis was established on the basis of a history of discrete or repetitive trauma to the elbow tip, absence of systemic rheumatic disease, bursal swelling, and bursal fluid findings that included low leucocyte count, predominance of mononuclear cells, evidence of haemorrhage, absence of crystals by polarizing microscopy, and negative culture. ${ }^{1}$

After initial fluid aspiration patients were instructed to avoid leaning on the elbow, but fluid reaccumulated in all but one case, prompting consideration of further therapy. When no contraindications to local corticosteroid treatment were present,

Accepted for publication 10 February 1983.

Correspondence to J. J. Canoso, MD, D10-93, Boston Veterans Administration Medical Center, 150S Huntington Avenue, Boston, MA 02130, USA. some patients then received $20 \mathrm{mg}$ of triamcinolone hexacetonide by intrabursal injection.

A follow-up survey was conducted by one of the authors (PSW), who was unaware of the elbow originally involved and the treatment used. The mean follow-up period was 31 months with a range of 6 to 62 months.

\section{Results}

PATIENTS

Final data were obtained for $49(82 \%)$ of the original 60 patients; 42 were examined and 7 were questioned by telephone. Two of these patients had undergone bursectomy and will not further be considered here. Of the remaining 11 patients 4 had died of unrelated disease and 7 could not be located.

Twenty-two patients (group I) had been given no therapy beyond a single bursal aspiration; 25 (group II) had received intrabursal triamcinolone hexacetonide at a mean interval of 7 days following initial aspiration. Age, duration of symptoms, and bursal fluid findings were similar in the 2 groups (Table 1).

\section{RESPONSE TO TREATMENT}

In group I, treated by aspiration alone, the percentage of patients with bursal effusion slowly declined over the entire period of observation (Fig. 1). In contrast there was a marked and abrupt reduction in the percentage of group II patients with effusion one week following steroid injection. Except for one 
Table 1 Traumatic olecranon bursitis: clinical and bursal fluid characteristics and treatment groups

\begin{tabular}{|c|c|c|}
\hline & $\begin{array}{l}\text { Aspiration } \\
\text { alone } \\
\text { (group I) }\end{array}$ & $\begin{array}{l}\text { Corticosteroid } \\
\text { injection } \\
\text { (group II) }\end{array}$ \\
\hline Number of patients & 22 & 25 \\
\hline Age $^{*}$ & $59(36-82)$ & $56(41-82)$ \\
\hline \multicolumn{3}{|l|}{ Bursal fluid findings $\ddagger$} \\
\hline $\mathrm{WBC} / \mathrm{mm}^{3}$ & $600(50-3450)$ & $300(0-11700)$ \\
\hline $1 \%$ PMN & $12(0-60)$ & $4(0-64)$ \\
\hline $\mathrm{RBC} / \mathrm{mm}^{3}$. & 28000 & 21700 \\
\hline & $\left(450-\right.$ Hct $\left.40 \%{ }^{\dagger}\right)$ & $200-888000)$ \\
\hline \multicolumn{3}{|l|}{ Intervals (days) $\ddagger$} \\
\hline $\begin{array}{l}\text { Onset of symptoms- } \\
\text { initial aspiration }\end{array}$ & $14(2-180)$ & $11(1-90)$ \\
\hline $\begin{array}{l}\text { Initial aspiration- } \\
\text { corticosteroid injection }\end{array}$ & NA & $7(0-42)$ \\
\hline
\end{tabular}

* Data represent mean and range.

¥ Data represent median and range.

† Hct value rather than actual cell count was used for one grossly haemorhagic fluid.

$\mathrm{NA}=$ Not applicable. $\mathrm{PMN}=$ polymorphonuclear leucocytes. $\mathrm{RBC}=$ red blood corpuscles

SI conversion $=$ blood cells $\times 10^{6}=$ number $/ 1$.

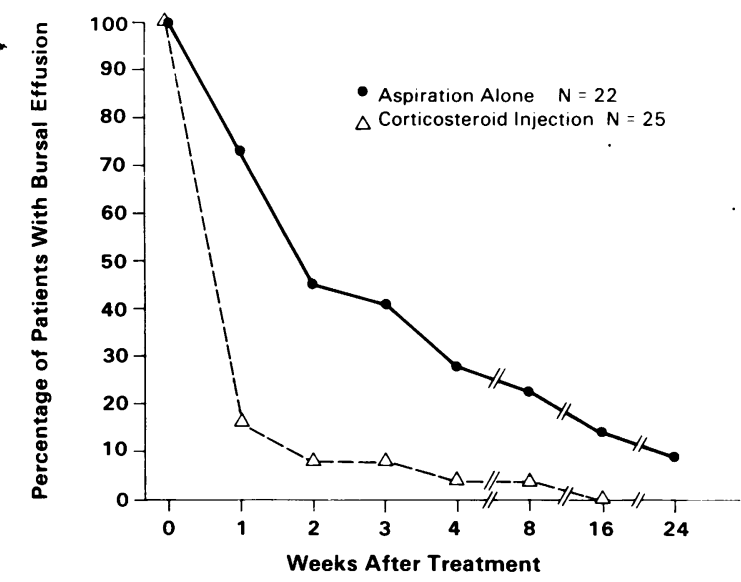

Fig. 1 Bursal effusion in patients with traumatic olecranon bursitis. Note that weeks of follow-up are measured from diagnostic aspiration in patients treated without corticosteroids and from corticosteroid injection in patients treated with local corticosteroid. Modified life table analysis. ${ }^{3}$

patient in group I the bursitis eventually resolved in all cases. Self-limited relapse occurred in 3 cases in group I and 2 in group II.

\section{COMPLICATIONS OF TREATMENT}

Three group II patients developed septic bursitis at 1 week, 2 months, and 4 months, respectively, following corticosteroid injection. Cultures of bursal fluid

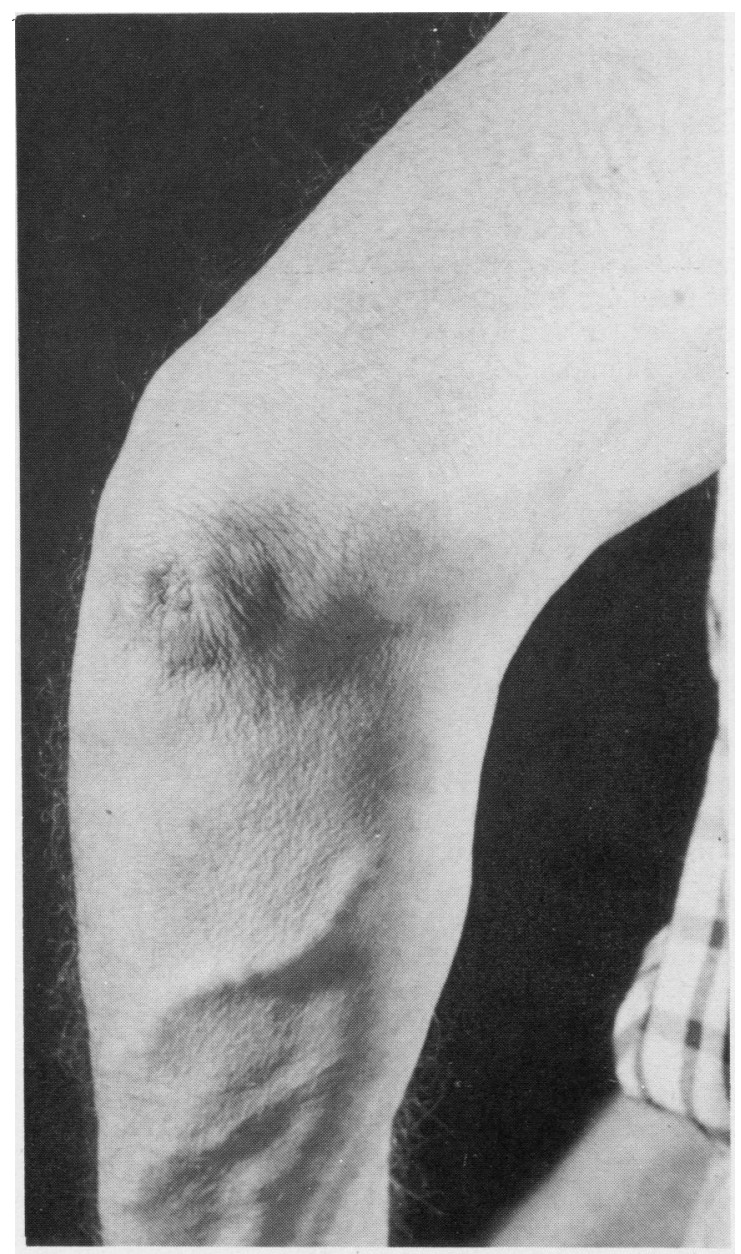

Fig. 2 Thin, atrophic skin at elbow tip surrounded by discolouration in a patient treated with intrabursal corticosteroids.

grew penicillin-resistant Staphylococcus aureus. One of these patients was treated elsewhere, and his infection was unknown to the authors until the time of this survey. The other 2 patients have been previously reported on. ${ }^{4}$ No instance of septic bursitis occurred in group $\mathrm{I}$.

Skin atrophy, which was defined as thinning and discolouration of the skin overlying the olecranon process (Fig. 2), was present in 5 patients who received corticosteroids but not in patients treated by aspiration alone. In 3 patients the atrophy was marked, while in the other 2 it was subtle. In one patient skin atrophy was associated with pain.

Chronic pain on leaning on the elbow was noted by 2 patients in group I and 7 patients in group II. Both 
those in group I but none of those in group 2 complained of local pain at the initial examination.

\section{Discussion}

Traumatic bursitis is the commonest condition affecting the subcutaneous olecranon bursa. ${ }^{5}$ Recommended forms of therapy include drainage of the bursa ${ }^{6}$ intrabursal injection of corticosteroid at a dose of $10^{7}$ to $40^{8} \mathrm{mg}$ of triamcinolone hexacetonide equivalent, and partial resection of the olecranon process leaving the bursa intact. ${ }^{9}$ No controlled trials of treatment of traumatic bursitis have been published.

Ours is a retrospective survey of patients treated by aspiration alone or by aspiration plus local corticosteroid. Decisions on treatment were not random. In spite of these shortcomings the lack of published data on this condition led us to report our experience of 47 patients with traumatic bursitis.

There was a clear difference between the patients treated by aspiration alone and the patients who also received corticosteroids, as depicted by life table analysis. Since an average of 7 days elapsed between initial aspiration and corticosteroid injection, the 2 groups of patients are not strictly comparable. However, this 7-day period would not account for the difference in shape between the 2 curves in Fig. 1, in particular the dramatic decrease in bursal effusions within 1 week of corticosteroid treatment.

The second, more important, and unexpected finding was the high rate of long-term side effects of corticosteroids injection. In most instances they had not been recognised before, since patients were discharged from the clinic when a satisfactory response to treatment (disappearance of effusion) was achieved, and complications usually occurred later in the course.

Skin atrophy is a well-known complication of subcutaneous, ${ }^{10}$ tendinous, ${ }^{11}$ and articular ${ }^{12}$ injection of corticosteroid. Its occurrence following injections of the olecranon bursa could have been predicted, since the bursal lining rests directly on the deep dermis with little or no fatty subcutaneous interposed. ${ }^{13}$

A surprising finding was the frequent complication of pain when leaning on the elbow in patients treated with intrabursal corticosteroids. Circumstantial evidence suggests that this pain may relate to clinical or subclinical skin atrophy.
The incidence of septic bursitis may have been increased by our use of a relatively high dose of corticosteroid. While lower doses might avoid this risk, the olecranon bursa, poorly protected and subject to frequent trauma, is much more prone to infection than other synovial structures. Even low-dose corticosteroid may be risky.

We conclude from our survey that, while local corticosteroid is an effective treatment for traumatic olecranon bursitis, the high incidence of side effects and the self-limiting nature of the condition indicate conservative therapy for most patients.

A prospective trial with lower doses of corticosteroids is warranted.

We thank Carol M. Barnstead for expert secretarial help.

This work was supported by grants from the United States Public Health Institutes of Arthritis, Metabolic, and Digestive Diseases, National Institutes of Health (TI AM 5288); the Multipurpose Arthritis Center Grant AM-20613; the Massachusetts Chapter of the Arthritis Foundation, and the Arthritis Foundation.

\section{References}

1 Canoso J J. Idiopathic or traumatic olecranon bursitis. Arthritis Rheum 1977; 20: 1213-6.

2 Saini M, Canoso J J. Traumatic olecranon bursitis. Radiologic observations. Acta Radiol (Diagn) (Stokh) 1982; 23: 255-8.

3 Merrell M, Shulman L E. Determination of prognosis in chronic disease, illustrated by systemic lupus erythematosus. J Chronic Dis 1955; 1: 12-32.

4 Canoso J J, Sheckman P R. Septic subcutaneous bursitis. Report of sixteen cases. J Rheumatol 1979; 6: 96-102.

5 Canoso J J, Yood R A. Reaction of superficial bursae in reponse to specific disease stimuli. Arthritis Rheum 1979; 22: 1361-4.

6 Fisher R H. Conservative treatment of distended patellar and olecranon bursa. Clin Orthop 1977; 123: 98.

7 Hollander J L. Arthrocentesis and intrasynovial therapy. In: McCarty D J, ed. Arthritis and allied conditions. Philadelphia: Lea and Febiger, 1979: 402-14.

8 The Upjohn Company. Intrasynovial injection techniques. 1975 . 13.

9 Quaile J B, Robinson M P. A useful procedure in the treatment of chronic olecranon bursitis. Injury 1978; 9: 299-302.

10 Goldman L. Reactions following intralesional and sublesional injections of corticosteroids. JAMA 1963; 182: 613-6.

11 Lund I M, Donde R, Knudsen B A. Persistent local cutaneous atrophy following corticosteroid injection for tendinitis. Rheumatol Rehabil 1979; 18: 91-3.

12 Cassidy J T, Bole G G. Cutaneous atrophy secondary to intraarticular corticosteroid administration. Ann Intern Med 1966; 65: 1008-18.

13 Canoso J J. Bursae, tendons and ligaments. Clin Rheum Dis 1981; 7: 189-221. 